DOI: $10.15503 /$ jecs20141-226-241

226

Expression

\title{
DEFINING INTERDISCIPLINARITY AND INDENTIFYING RESEARCH DIRECTIONS IN JANI CHRISTOU'S STRYCHNINE LADY
}

\author{
MARIA YEROSIMOU, PHD \\ Faculty of Music Goldsmiths University of London, \\ Lewisham Way, New Cross, London, UK \\ E mail address: mup01my@gold.ac.uk
}

ABSTRACT

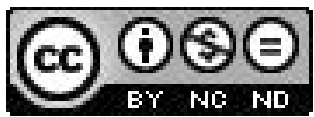

Jani Christou was a major Greek composer, whose unusual, yet promising career was brought to an end after his untimely death in 1970 at the age of 44 . His challenging and speculative output has intrigued generation of young music scholars; however, J. Christou's work remains imperfectly and only patchily known and understood, especially outside Greece. This is partly because of the interdisciplinary nature of his late works which reduces the possibility of potential researchers who will academically establish J. Christou's distinguished output. The aim of the present paper is to present and analyse parts of Strychnine Lady, a work composed in 1967 in order to propose research directions in an effort to confirm J. Christou's posthumous reputation.

Key words: Experimental music theatre, avant garde music, contemporary music, 20th century music, Greek avant garde composer

\section{INTRODUCTION}

On the $8^{\text {th }}$ January 1970 an unusual and thrilling talent was lost in a car accident: the composer Jani Christou. J. Christou was a major composer and philosopher, whose unusual, yet promising career was brought to an end after his untimely death at the age of 44 . In his late works particularly J. Christou brought into conjunction his deep immersion in philosophical and psychological studies, including the ideas of Carl Jung and alchemy, with avant-garde musical and dramatic materials and means. It is crucial to mention that the composer invented a completely personal and ground-breaking music notation system to vividly and thoroughly describe his concepts.

\section{Biography}

J. Christou was born of Greek parents at Heliopolis, N.E. of Egypt's Cairo on $8^{\text {th }}$ January 1926. As a child he was well educated, receiving his primary education at the English Victoria College in Alexandria. He started having piano lessons in 1931 and for a period of time he studied with the famous contemporary pianist Gina Bachauer, who introduced him to music theory. J. Christou started compos- 
ing at an early age. In 1945, he moved to Kings College, Cambridge in England to study philosophy and formal logic, under Ludwig Wittgenstein and Bertrand Russell (Minou, 2010) and obtained an MA degree in philosophy in 1948. Simultaneously, he also started studying music on a private basis with Hans F. Redlich, who was a well-known musicologist and had been a student of Alban Berg. He later went to Rome to study orchestration with Angelo F. Lavagnino.

During 1951-1954 J. Christou travelled widely across Europe, ending with a short stay at Zurich, where it is believed that he met Carl Jung and attended several lectures in psychology with him, although this information is not confirmed by evidence. His brother, Evanghelos - who himself was a student of C. Jung had greatly encouraged J. Christou's studies in psychology.

J. Christou returned to Alexandria in 1951 where he devoted himself to composition. In 1956 he married his childhood friend Theresia Horemi, an exceptional young painter from Chios. In the same year, his brother was killed at a car accident, a fact that had a deep effect on J. Christou. Evangelos was considered as his spiritual mentor who had a great role in his creative thinking and his death had a deep effect that stigmatised J. Christou. It is worth mentioning that Evanghelos's book The Logos of the Soul was a posthumous publication edited and curated by J. Christou himself. In 1960 he moved permanently to Greece, dividing his time between Chios and Athens before eventually settling in the latter due to his increasing professional demands.

J. Christou and his wife Theresia were killed in a car accident after celebrating the composer's name day. J. Christou died at the age of forty four on his birthday, being already one of the leading composers of his time. His compositional and pre-compositional work is kept in his personal archive in Athens and managed by the composer's daughter Sandra.

\section{J. Christou today}

Today, J. Christou is considered as a major composer and a leading figure in post-war Greek music (Sakallieros, \& Kyriakos, 2008). Nevertheless, J. Christou's work remains imperfectly and only patchily known and understood, especially outside Greece and his name is generally unknown within international music communities. Ironically, at the time of his death, the most ambitious project of his music career - a large scale contemporary opera based on Aeschylus's Oresteia (1967-70) - was going to be premiered at the prestigious English Bach Festival in London in April 1970; performances were also scheduled to take place in Japan, France, Scandinavia and the USA. Thus, despite being greatly honoured in contemporary music circles in the sixties, J. Christou's unfortunate and premature death brought to an end a promising career and secreted a remarkable output.

J. Christou's death is not the only reason that his work has not yet been thoroughly appreciated; the author would like to stress the issue of interdisciplinarity as regards the composer's late works, created 1965-1968. There is a special relation in J. Christou's musical compositions with other, non-musical systems of thought. Any analytical attempt that does not include these systems could not be valid, in 
view of the fact that J. Christou's works could not be comprehensively analysed by the traditional musicological methodologies. Thus, musical knowledge exclusively is not sufficient and a researcher should be prepared to study extensively other, non-musical and performance areas; a fact that reduces the range of possible researches on the topic.

\section{Aims}

This paper focuses on Strychnine Lady (1967), a work included in a group of compositions which are described by the composer himself as stage-rituals and aim to lead the performers and audience to a transcendent stage in order to communicate primeval and archetypal elements of the unconscious. The interdisciplinary nature of the work, as previously stated, requires a special analytical approach, which should include extended research in other disciplines. The aim here is to present and analyse selected parts of Strychnine Lady, in the hope of furthering research in the field of J. Christou's studies by proposing interdisciplinary research directions, derived from the music score.

\section{RITUALISTIC QUALITIES}

\section{Rehearsal marks 9-13}

In the next paragraphs there will be an attempt at describing and analysing the rehearsal marks ${ }^{1}$ 9-13 of J. Christou's Strychnine Lady. These particular Rehearsal marks have been chosen as they appear to include some interesting elements in regards to the definition of the work and its perception. In particular, they could be references to mystical, mysterious and ritualistic qualities. Before any analytical attempt or an outline of any context, a description of the content of these Rehearsal marks is considered as essential.

At the Rehearsal marks 9-13, the viola player is required to play just one continuous note. According to the music score, J. Christou gives the following instructions:

- deeply meditative

- unreal

- soft

A few moments later, four actors enter the stage slowly in a row and start reciting a Latin text, each one at a different speed. They slowly move towards the piano, reciting the Latin text in a crescendo that leads to a shout across the strings of the piano.

This short moment brings into sight a few attention-grabbing elements: Firstly, the instructions that the composer gives to the solo viola player are quite unusual; they concern a mood and an ambiance rather than a playing technique, excluding 'soft'. In other words, the viola player has to enter a meditative mood and set her playing of the particular note in the specific space. A question arises about why the composer uses these particular words in describing the playing of the viola note. The words "unreal" and "deeply meditative" are usually used to describe

The term "rehearsal marks" refer to the different sections of Strychnine Lady's music score. 


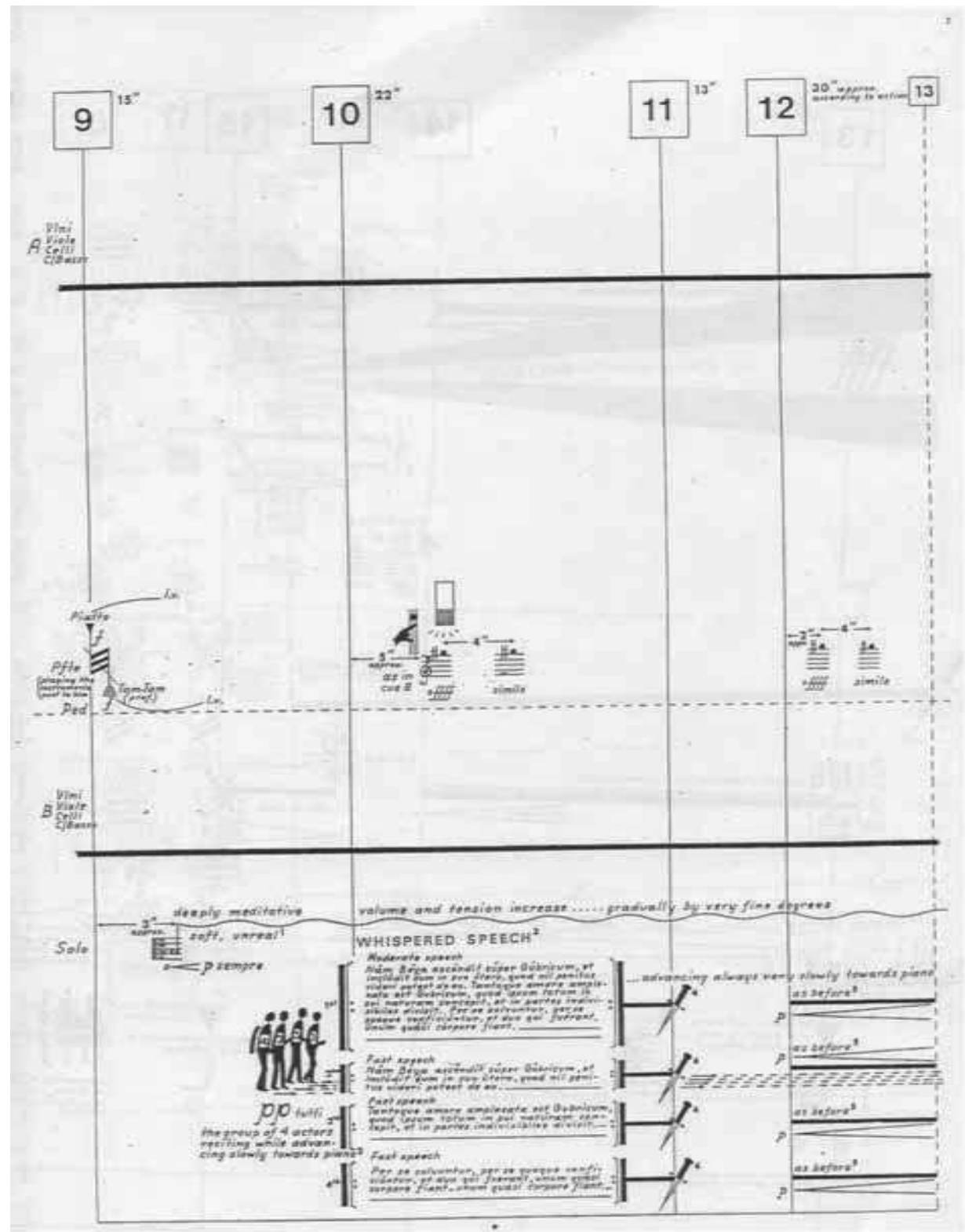

Example 1. J. Christou, Strychnine Lady, Rehearsal marks 9 - 13.

Source: Christou, 1973, p. 7.

situations usually related to the extraordinary. There is also a connection between the word "meditative" and the viola's continuous playing of just one note; it could be connected with eastern mediation practices, such as mantras based on just one sustained note, creating harmonics and vibration on a specific frequency. 
The entrance of the four actors also contributes to the creation of an unrealistic atmosphere associated with the extraordinary. They move slowly in a row, a scene that relates to movements drawn from ancient ceremonies. There are many scenes in various ancient cultures that this movement resembles. One of these could be the entrance of the chorus in ancient Greek tragedy; a scene strictly connected to ritualistic practices.

During their entrance, the actors recite a Latin text. The use of the Latin language is very interesting and needs to be discussed for many reasons. To begin, Latin is no longer used, it is in other words a 'dead' language, and it seems as though J. Christou is bringing back to life something from the past, reaching back through the centuries. This awakens a mysterious spirit, since there is a bringing of the past into the future, creating a strange but still interesting redefinition of time. The broad characterisation of Latin as 'dead' creates on its own a weird sense of bringing the world of the 'dead' into the living world, a fact that creates an atmosphere connected with ritual.

Concerned with the ritual, another important aspect of Latin should be mentioned. Latin is the language used in many kinds and types of ceremonies and rituals throughout the centuries, starting from the Roman-Catholic liturgy. It is the language used in exorcisms, alchemical texts and mystical ceremonies. It is also believed to have a divine nature (Sheridan, 1994). The particular text used in this small part of the Strychnine Lady presents the story of Gabricius, as it is described in the ancient alchemical text Rosarium Philosophorum (Jung, 1952). There, Beya embraces Gabricus with such overwhelming love that absorbs him completely into her womb, transforming him into many invisible pieces. Following this union, the formerly two different persons are now combined, forming a new creature. The content of this bizarre story also relates to the extraordinary and follows the same mood as the previous elements outlined; an atmosphere that could be characterised as ritualistic, mysterious and potentially mystical. These characterisations are supported by the context of the text. The story of Beya and Gabricius, as mentioned above, is described in the medieval alchemical text Rosarium Philosophorum.

The practice of alchemy appears to be rather ancient. The Egyptians, Greeks, Romans, Chinese, and early Arab cultures all engaged in alchemical investigations. Alchemists had a number of goals in their work. Several of them were seeking a process which would turn base metals like lead into gold or silver. In addition they had panacea as a goal also known as a cure-all, which would, in theory, extend life for an indefinite period. In Europe, alchemy experienced a resurgence during the medieval period, as a result of an interest in translating ancient texts which exposed people to the concepts of alchemy. In addition to being an exploration of chemistry, medieval alchemy was also concerned with philosophy and metaphysics, and, as chemistry commenced to emerge as an independent discipline, the exploration of alchemy became metaphysical. People who view alchemy as metaphysical consider alchemical terms as metaphors, and not factual references to substances.

Thus, a very important part of Alchemy is strongly connected to and fundamentally deals with the basic mysteries of life, as well as with transcendental mysticism (Miller, 1986), something that strengthens the mystical dimension of this particular part of the Strychnine Lady. It should be also mentioned that this story is included in C. Jung's Psychology and Alchemy (1952). C. Jung states that this 
bizarre union of Beya and Gabricius is an entirely symbolic incest of the conscious that descents into the unconscious (Sakallieros, \&Kyriakos, 2008). C. Jung won't be analysed further in the present writing, but there will be just a reference to the Jungian world of symbols and the unconscious, a reference that awakes, as the previous mentioned elements, the sense of the mysterious and the mystical.

\section{Rehearsal Marks 76-78}

Referring to the ritual element, there is another part that could be characterised as ritualistic. The part covers the Rehearsal marks 76-78.

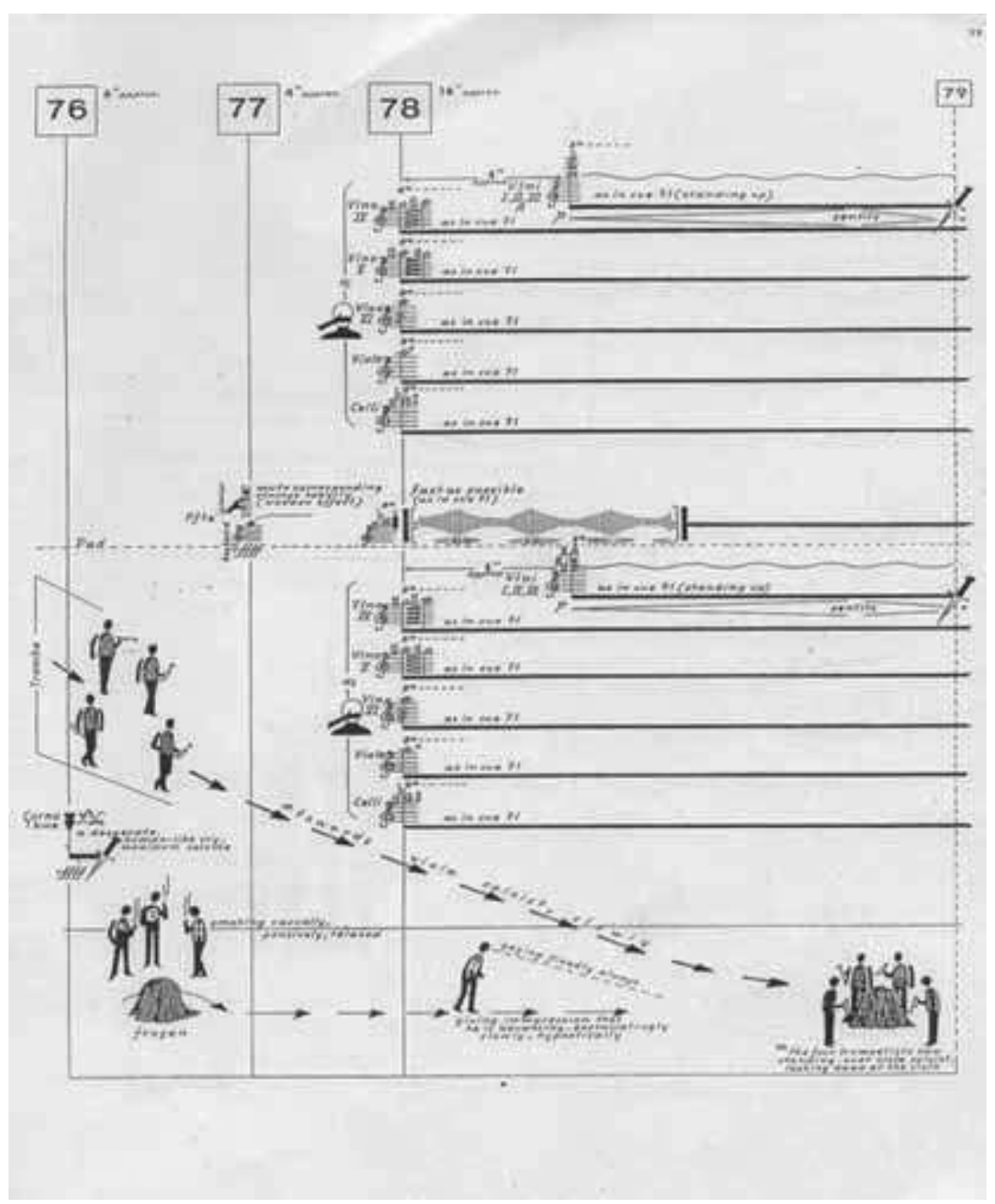

Example 2. J. Christou, Strychnine Lady, Rehearsal marks 76-79.

Source: Christou, 1973, p. 39. 
The Rehearsal marks 76 starts with "a desperate, human-like cry" at maximum volume by the horn and the trombone. The viola soloist lies on the floor, covered with a red cloth whilst three actors are smoking "casually", "pensively" and "relaxed". At the same moment, four trumpeters advance "excruciatingly" slowly, as if hypnotised, gravely towards the covered viola soloist. A fourth actor has by-passed the viola soloist, and is gazing fixedly, giving the impression that he is advancing also "excruciatingly-slowly-hypnotically". At Rehearsal marks 78 the trumpeters have reached the viola soloist and stand over her, in a circle, looking down at the cloth.

The above scene closely resembles a funeral ceremony. The viola soloist is collapsed on the floor and covered with a red cloth. The choice of red colour for the cloth is not unintentional. Red is considered as a sacred colour and is linked with many symbols. Red throughout the development of civilisation has had connotations with the sacred. Red is associated, from ancient times, with ceremonies of human or animal sacrifice and usually represents blood. It is also the colour of fire, another sacred symbol and is very often used in funerals, a fact that enhances the assumption of the "funeral" semblance at the Rehearsal marks 76-78.

Also, the slow movement of the trumpeters towards the red-cloth covered viola player and the "desperate, human-voice cry" of horn and trombone bear a resemblance to pictures from a funeral march, where people move slowly and desperate cries accompany the whole ceremony.

The above reference to funeral ceremonies and realistic events such as a funeral march are in contrast with the three actors who stand and smoke casually, acting as if nothing is happening. Also, there is a fourth actor who is not related at all with all the events and actions taking place, he is like a being in a world of his own. The fact that there are actions taking place at the same time with no communication or logical connection between them could be a characteristic of a ritual. Also, this illogical development of the events refers to the previously mentioned definition of a ritual.

\section{Strychnine lady and theatricality}

In Strychnine Lady a co-existence of different performance elements is observed. Christou requires four actors and one actress in addition to the musicians, and demands from all of them to use a broad range of expressive means, apart from the ordinary acts required (for example playing musical instruments).

\section{Rehearsal marks 69-70}

In rehearsal marks (=Rehearsal marks) 69-70 some examples of the coexistence of those different elements is observed, as they present an action going beyond what is normally perceived as music performance. In the next paragraph the author sets out to describe this moment.

At the Rehearsal marks 69 the following directions are given to the horn and the trombone players: "walking slowly through auditorium". The viola player is collapsed and remains "frozen" on the floor, whilst three actors, 2, 3 \& 4 are smoking casually. Another actor walks by the viola player and, "gazing always", 


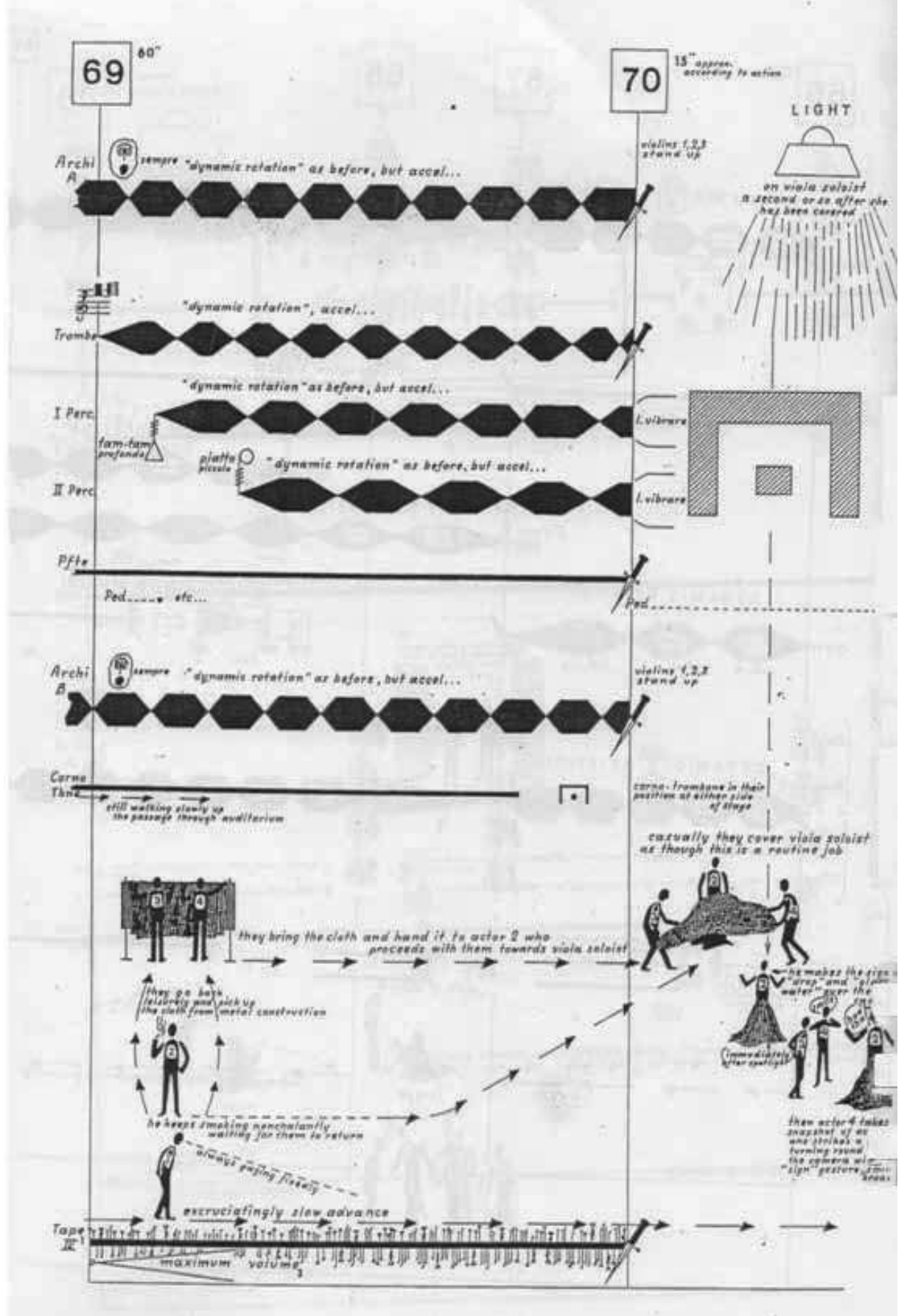

Example 3. J. Christou, Strychnine Lady, Rehearsal marks 69-70. Source: Christou, 1973, p. 36. 
keeps advancing excruciatingly slowly. In Rehearsal marks 69, two of the smoking actors go back "leisurely" and pick up a red cloth that is placed on a metal construction, whilst the remaining actor keeps smoking "nonchalantly", waiting for them to return. In the meantime, the horn and trombone player are still walking slowly through auditorium and actor 1 also walks slowly, always gazing "fixedly". At Rehearsal marks 70, violins 1, 2 \& 3 to stand up. The three previously smoking actors are now covering casually the viola soloist "as though this is a routine job". A second or so after she has been covered, a spotlight comes up on the viola player Actor 2 makes gestures on the same motives of the preciously performed Rehearsal marks 31. Subsequently, actor 4 takes a snapshot, using a camera, of the covered viola soloist and the remaining actors.

There is a special stage action as regards the soloist viola player; in a usual music piece it would be enough to play her instrument and produce music at an acoustic level. But J. Christou goes beyond that and requires a kind of a theatrical action. At this particular part described above, she is not playing her viola and she is sitting frozen on the floor, after she has collapsed. This can be characterised as a theatrical action, since it follows specific instructions related with body movement and directed stage performance. Also, the viola player is acting as a character, in other words, represents someone else than herself. This strongly contrasts the usual role of a musician, as in that case, a musician is representing himself/ herself playing a music piece. Particularly, in music performance a performer does an action for the audience. In the theatrical performance's case, a performer does as action for the audience as a character.

Another theatrical aspect of the Strychnine Lady is the use of actors. In Rehearsal marks 69-70 there are four actors, required to act as characters following directed actions. This adds to the theatricality of the Strychnine Lady, since the use of actors gives a dramatic hypostasis to the play.

Another important factor that should be taken into consideration is the use of extra-musical objects. In the part described above, a red cloth and a metal construction are used clearly as scenic objects and not as means to create sound. The red cloth is used to cover the frozen viola player and its meaning can lead in many different directions. There is an issue concerning the color of the cloth, since red color has many symbolisations. It could recall pictures from ancient theatre performance practices which were connected with rituals of sacrifices, therefore red could represent blood. This notion strengthens the theatrical hypostasis of the red cloth.

The whole action does not resemble at all a usual music performance. It is clear from this part that the work does not concern a production of sound solely, given that it has a narrative sequence and staged action. It is also understandable that Strychnine Lady requires the involvement of the "eye" as well, not just the "ear", as in typical music performances. At this point, it seems appropriate to look into the term "theatre". The word "theatre" is derived from the ancient Greek $\theta \dot{a} a t \rho o v$ (théatron, "a place for viewing") and Acáouar (theáomai, "to see", "to watch", "to observe"). Hence, "theatre" involves viewing and observation so in this sense, Strychnine Lady could be said to be theatrical. 


\section{PSYCHOLOGICAL ASPECTS}

\section{Rehearsal marks $44-45$}

In the Rehearsal marks 44-45 some notions of psychology can be observed. J. Christou's relation to psychology and C. Jung is known and obvious in other parts of the work, taking into consideration the fore-mentioned story of Beya and Gabricius, included in Psychology and Alchemy (Jung, 1952). The following paragraphs present an attempt at indentifying where these two rehearsal marks lead in relation to psychological elements, psychological conditions and others.

Firstly, a description of the Rehearsal marks is required in order to realise what happens in this part of Strychnine Lady. At the end of Rehearsal marks 43, a previously immobile, with a soft, child-like smile actor (actor 1) has a sudden, soundless panic attack. The actress sitting in the audience screams, so does actor 1 and at the same moment, the viola soloist stops smiling (half smile vanishes), an action that has taken place in the previous Rehearsal marks and starts playing her viola with "sudden aggressiveness". Actor 1 stays immobile with an expression of horror whilst the three other actors are smoking casually, according to the composer, "in a silent action, miming". The soloists keep playing furiously, while actor 1 looks at her feet, slowly raises his head and gazes at her hips.

It is interesting to discuss the directions that the composer gives to the performers. In the soloist's case, directions include the following words:

- aggressiveness

- erotic ferocity

- obsessive relentlessness

- hysteria

- threats alarm savage desire

It is clear from the above that the composer wants to describe the psychological condition of an action and does not give aesthetic directions on the performance. The words described are quite unusual and refer to a very special emotional and psychological condition in which the performers have to bring themselves into, in order to achieve the requested performance result. The term "erotic ferocity" refers to an emotional condition that is very specific and not a general emotional direction. The soloist needs to experience in her inner world this situation; otherwise there is no other way to perform it in the correct manner. This also applies to the direction of "hysteria" and "aggressive relentlessness", as these are special emotional situations that demand an experience rather than a mimetic action, otherwise they cannot be effectively produced. This makes the performer's role much more difficult, as they are required not only to perform, but to experience this particular emotional situation, to have this situation psychologically controlled and to perform it at the same time in an environment of a pre-arranged and scheduled performance.

All of the above concern in the same way the actors. They have to act casually and smoke at the same time that the soloist is under "hysteria", actor 1 and the actress in the audience are screaming and the bass drum player is playing aggressively at maximum volume. They need to remain in the same stage of nonchalance 


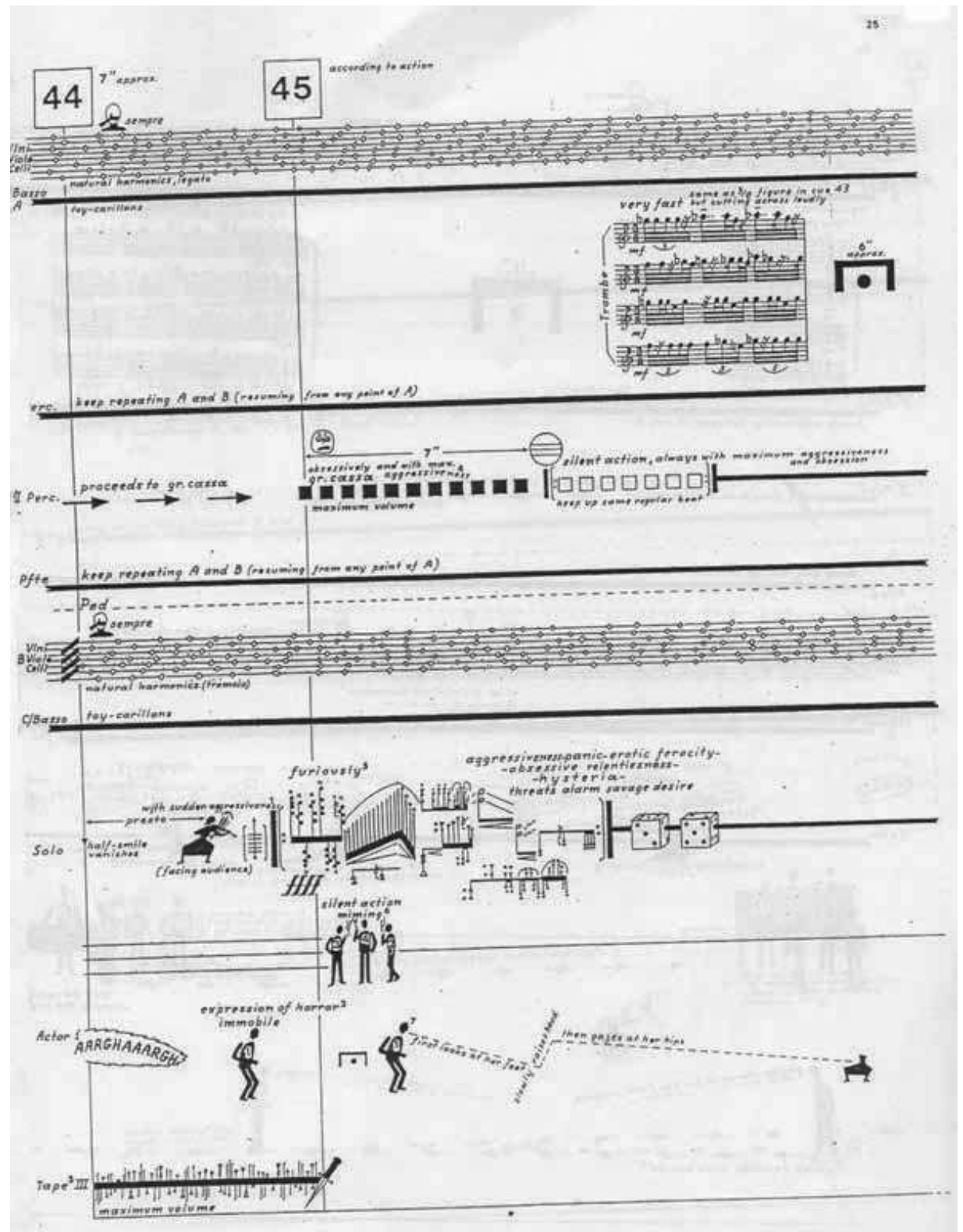

Example 4. J. Christou, Strychnine Lady, Rehearsal marks 44-45.

Source: Christou, 1973, p. 36.

and experience an emotion of numbness. The difficulty in this action for the actors is how to experience numbness, since there is no way of not being affected by the other actions on stage, which are completely opposite psychologically.

What is very interesting is how the spectator of the Strychnine Lady is affected by all of the above. They experience actions out of the every-day experience, com- 
pletely different and with no connection between them: panic, screaming, hysteria, numbness, impassiveness, horror, threat. All these form an experience that cannot leave them unaffected. It affects their psychology in ways that they cannot control anymore, even when they leave the hall where the performance is taking place. This situation concerns feelings and emotions that are represented to the spectator, which are out of their everyday life situations; they usually exist in a deeper level which J. Christou brings to the surface.

Emotions like panic, horror and hysteria have a primitive hypostasis they are usually related to the collective unconscious. The collective unconscious is a part of a theory that the Swiss psychiatrist C. Jung shaped in the first decades of the $20^{\text {th }}$ century. C. Jung distinguished the collective unconscious from the personal unconscious; the personal unconscious is a personal pool of experience inimitable to each individual, whereas the collective unconscious collects and organises those personal experiences in an analogous way with each associate of a particular species. For C. Jung: "My thesis then, is as follows: in addition to our immediate consciousness, which is of a thoroughly personal nature and which we believe to be the only empirical psyche (even if we tack on the personal unconscious as an appendix), there exists a second psychic system of a collective, universal, and impersonal nature which is identical in all individuals. This collective unconscious does not develop individually but is inherited. It consists of pre-existent forms, the archetypes, which can only become conscious secondarily and which give definite form to certain psychic contents" (Jung, 1996, p. 43) .

J. Christou had a special interest in C. Jung's theory, encouraged by his brother Evangelos (Evis) who he himself was a student at the C. Jung Institute. C. Jung's influence can be observed in many parts of the work, considering the alchemical text of Beya and Gabricius that is included in Psychology and Alchemy (Jung, 1952) and was outlined in previous writings concerning different parts of Strychnine Lady. C. Jung presents the story of Beya and Gabricus as a parallelism to the descent of the conscious area into the unconscious. C. Jung interprets the 'death' of Gabricius as follows: " On descending into the unconscious the conscious personality finds itself in a dangerous situation, for it seems as though it were extinguishing itself. It is the situation of the primitive hero who is devoured by the dragon. Since it is a question of the diminution or extinction of the conscious personality. . . the intentional or wanton provocation of this state is a sacrilege or a breach of a taboo, which is followed by the severest punishments" (Jung, 1952, p.319)

According to Curtiss Hoffman, C. Jung equates this myth with a process of individuation where the union of body and mind in the darkest part of the unconscious leads to a temporary elimination of consciousness, "followed by its redemption through the divine intercession of the Self" (Hoffman, 2002).

Considering the previously mentioned Jungian descent of the conscious into the unconscious, a parallelism can be found in the Rehearsal marks $44-45$ that this section is dealing with. In Rehearsal marks 44 the actors are smoking casually. This is considered to be an everyday action that could be assumed as an action and as a picture, to exist into the area of consciousness. On the other hand, during this action of consciousness, some other actions are taking place, that belong mostly to 
an unconscious area with primitive hypostasis. They start being developed based on a realistic event, something that could be another parallelism of the previous mentioned descent of the conscious into the unconscious area.

\section{Rehearsal marks 0-2}

There is an additional part that could be a parallel with the Jungian descent of the conscious to the unconscious: the beginning of the work. At Rehearsal marks 0 , actor 2 enters the stage casually and makes an announcement, saying that the work will not be performed for technical reasons; another work of the same composer will be performed in its place. The actor is prepared to give details for this replacement but he is interrupted by the protest of an actress sitting in the audience. Up to this point, the whole action belongs to the realm of consciousness, of the everyday life. What follows moves to the realm of the unconscious: two other actors, 3 and 4 , enter the stage and they start performing a sequence of slow, ritual movements, including the placement of a red cloth in the middle of the stage. During all these actions, actor 2 is staring, motionless, at the actress in the audience, while she also stares back at him coldly. It is clear that the whole scene deals with another level of reality which does not belong to the everyday realisation and does not follow any logic of consciousness. Subsequently, the music starts with percussion effects from the basses, pppp effects from the percussion and improvisation on motives from the violins, violas and celli, all following a crescendo. Actor 2, always staring at the actress in the audience, says that "there is absolutely no real cause of alarm".

The whole of this action, as mentioned before, could be a parallel with the Jungian representation of the story of Beya and Gabricius. The first part portrays a realistic event, Gabricius, the conscious. The second part portrays an unrealistic event, Beya, the unconscious, and finally the last part portrays the start of the transition of reception level, the symbolic union and the formation of the new being.

In a microscopic view, many parallels can be found with this story. It is interesting though that this parallel might exist in a macroscopic view as well. C. Jung describes this union as follows: "In order to enter into God's Kingdom the king [Gabricius] must transform himself into the prima materia in the body of his mother [Beya], and return to the dark initial state which the alchemists called the »chaos«. In this massa confusa the elements are in conflict and repel one another; all connections are dissolved. Dissolution is the prerequisite for redemption. The celebrant of the mysteries had to suffer a figurative death in order to attain transformation" (Jung, 1952, p.283).

In view of the above statement, could the start represent the absorption of Gabricius into the womb of Beya, in other words, the descent of the conscious into the unconscious?

In a macroscopic view of Strychnine Lady, some elements of C. Jung's statement can be found. First, there is no connection between the soloist, the actors and the music. Secondly, most of the times the events and gestures taking place are in conflict. Then, there are certainly situations that could be characterised as chaotic; and finally, the soloist carries out actions that lead to dissolution. Considering that the beginning of the work could be the descent of the conscious into the uncon- 


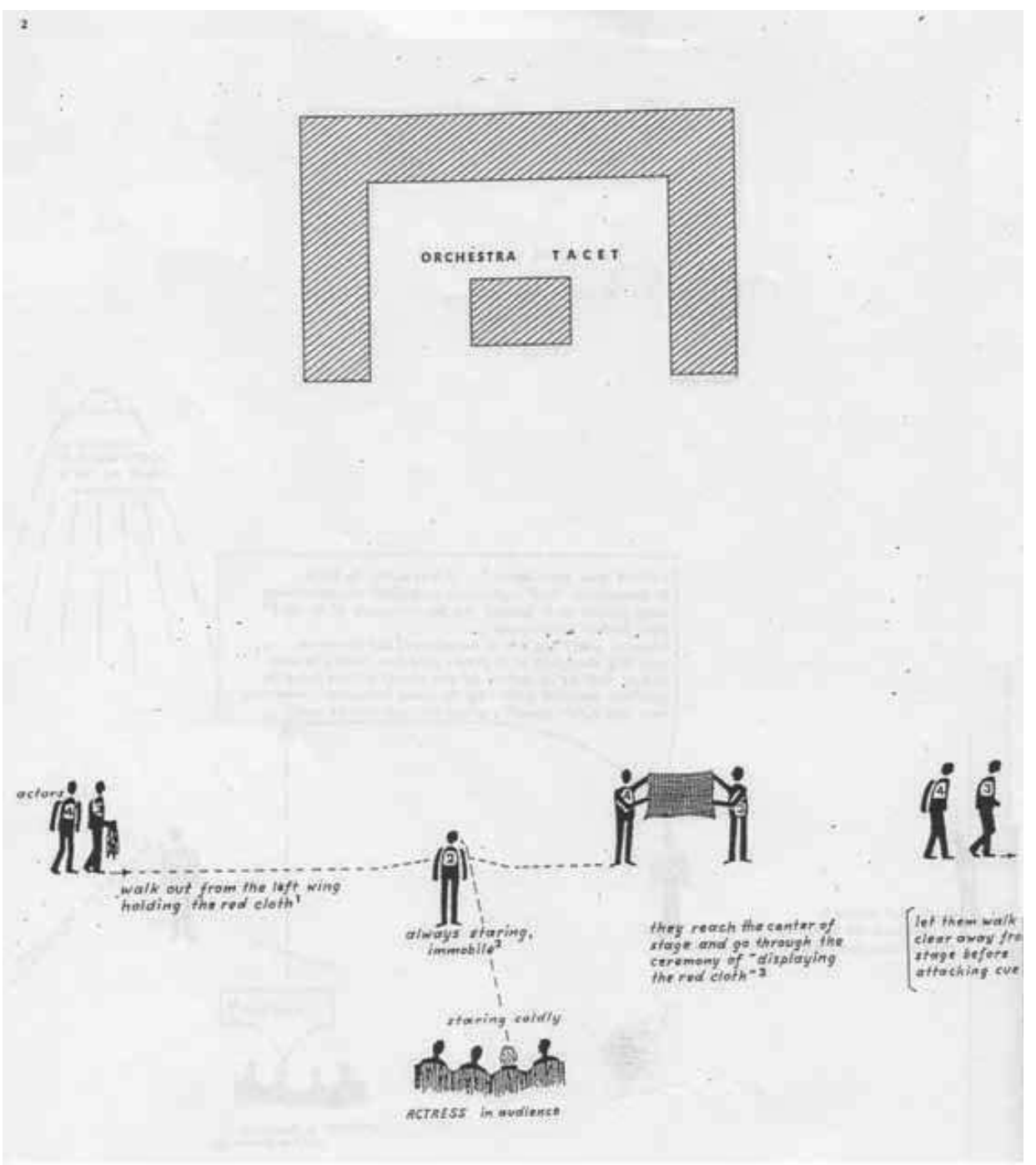

Example 5. J. Christou, Strychnine Lady, Rehearsal marks 0.

Source: Christou, 1973, p. 2.

scious, then the progression of the work could be the process of transformation, the return to "chaos", according to the above quote of C. Jung.

There is an argument that refers to the above hypothesis - that, macroscopically, Strychnine Lady could follow the Beya-Gabricius model. There is no writing on this subject in the composer's archive, thus there is no certainty that this hypothesis is valid. The story of Beya and Gabricius is only heard in a small part of Strychnine Lady and this particular fact does not allow any assumptions as far as the whole work is concerned. In my opinion, the fact that the story of Beya and Gabricius is included as performing material in the work is not unintentional. It 


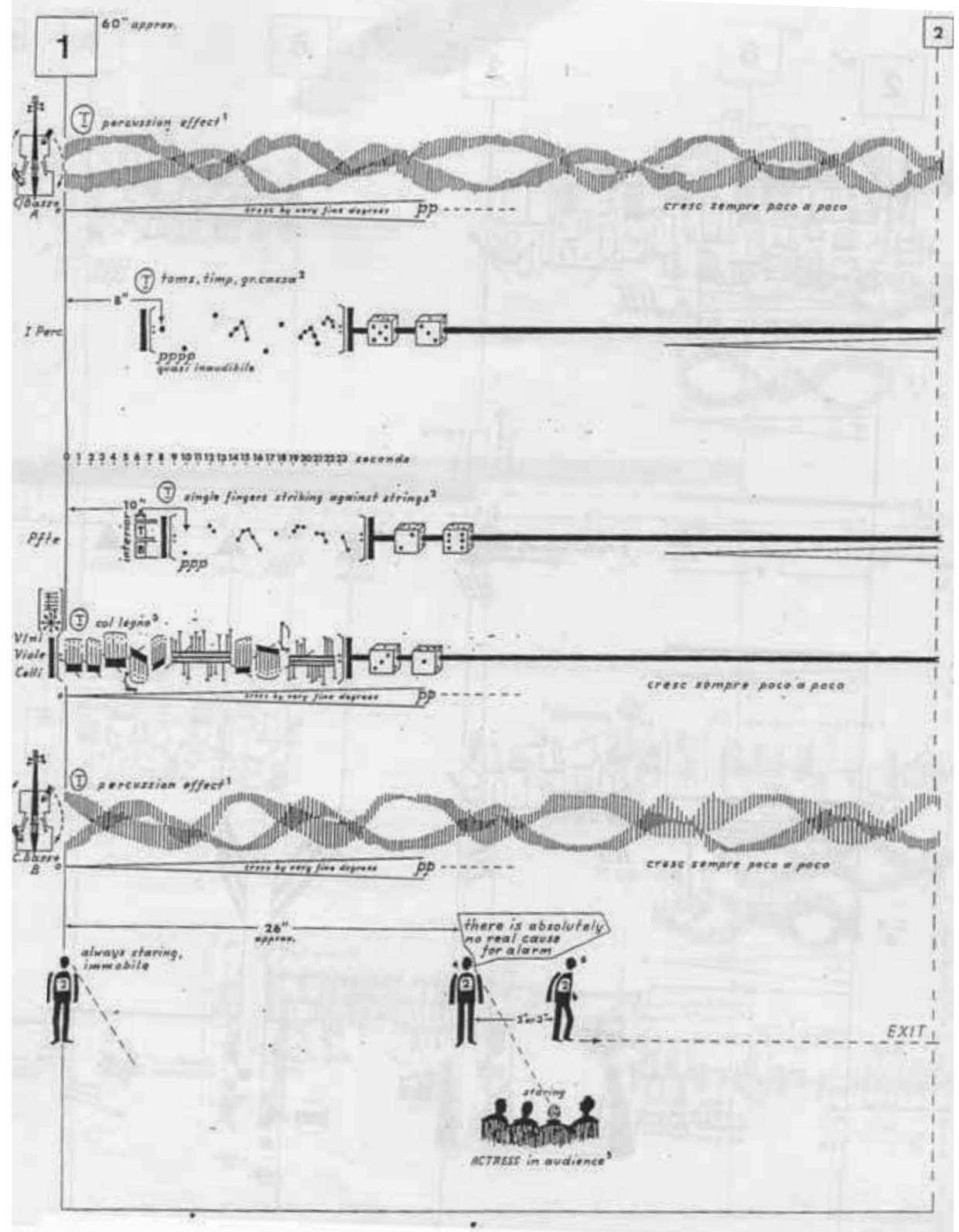

Example 6. J. Christou, Strychnine Lady, Rehearsal marks 1.

Source: Christou, 1973, p. 3.

would not be rational for a composer who gives instructions and guidelines in such detail, even including the performers' movements and facial expressions, to include something that does not have a deeper meaning. Also, J. Christou had studied C. Jung and alchemy for many years and would not choose to include a story 
in his work simply because he liked it, taking into consideration that he would work for a long time on each work in order to produce the exact result that he wanted. This conclusion results from studying the composer's archive, where all his preparations for each work are chronologically and carefully saved in detail, with separate files for each work.

\section{CONCLUSION}

J. Christou today is considered as a major composer and a leading figure in Greek post-war music. However, his work has not been thoroughly appreciated especially outside Greece. The author stresses the fact that there is a lack of published sources and academic research in the field of J. Christou's studies and states that this is partly because of the interdisciplinary nature of J. Christou's works that involve elements from other, non-musical areas. This paper analyses selected parts of Strychnine Lady in order to affirm interdisciplinarity in this particular work and mark research paths towards other directions. Finally, further research on the subject is suggested and particularly in the areas of rituals, dreams, dramatic aspects and psychology, in relation to the work.

\section{REFERENCES}

Christou, J. (1973). Strychnine Lady. Full score. London: J \& W. Chester Ltd.

Hoffman, C. (2002). The Seven Story Tower: A Mythic Journey Through Space and Time. New York: Basic Books.

Jung, C. G. (1952). Psychology and Alchemy. Princeton: Princeton University Press.

Jung, C. G. (1996). The Archetypes and the Collective Unconscious. London: Routledge.

Miller, I. (1986). Introduction to alchemy in Jungian psychology and, Alchemical Imagination: Making Psyche Matter. Retrieved from: http:/ / zero-point.tripod.com/alchemy/alchemyclass.html.

Minou, A. (2010). Sibyl's Leaves: understanding musical performance issues in Jani Christou's Anaparastasis III and Epicycle. PhD thesis. Goldsmiths University of London, Department of Music.

Sakalieros, G. \& Kyriakos, K. (2008). Musical conception, para-musical events and stage performance in Jani Christou's Strychnine Lady (1967). Proceedings of the fourth Conference on Interdisciplinary Musicology. Retrieved from: http://cim08.web.auth.gr/cim08_papers/Sakallieros-Kyriakos/SakallierosKyriakos.pdf.

Sheridan, M. (1994). Last rites for a dying language. The Independent. Retrieved from: http:/ / www.frcoulter.com/latin/foster/foster11.html. 